Int. J. Dev. Biol. 51: 753-759 (2007)

doi: $10.1387 /$ ijdb.072332sr

Developmental Expression Pattern

\title{
A comparative analysis of Meox1 and Meox2 in the developing somites and limbs of the chick embryo
}

\author{
SUSAN REIJNTJES ${ }^{1}$, SIGMAR STRICKER ${ }^{2}$ and BALJINDER S. MANKOO ${ }^{1, *}$ \\ ${ }^{1}$ King's College London, Randall Division of Cell and Molecular Biophysics, London, U.K. and \\ ${ }^{2}$ Max Planck Institute for Molecular Genetics, Berlin, Germany
}

\begin{abstract}
We have examined the expression pattern of the avian Meox 1 homeobox gene during early development and up to late limb bud stages. Its expression pattern indicates that it is involved in somite specification and differentiation. The domains of expression are similar but different to those of Meox2. Meox 1 is expressed from stage 6 in the pre-somitic mesoderm and as development proceeds, in the tail bud, the dermomyotome of the rostral somites and in the dermomyotome and sclerotome of the caudal somites, the lateral rectus muscle, truncus arteriosus of the heart and the limb buds. Unlike Meox1, Meox2 is not expressed in the pre-somitic mesoderm, but is expressed first in somites formed from stage 11 onwards. In the developing limb, both genes are expressed in the dorsal and ventral limb mesoderm in adjacent domains with a small region of overlap. In the limb bud, Meox 1 is co-expressed with Meox 2 but neither Meox gene is co-expressed with MyoD. These expression patterns suggest that these two genes have overlapping and distinct functions in development.
\end{abstract}

KEY WORDS: chick, somitogenesis, limb bud, sclerotome, dermomyotome

Meox1 and Meox2, formerly known as Mox1 and Mox2, are closely related homeobox genes with mesoderm and mesenchyme specific expression during mouse embryonic development (Candia et al., 1992). Mice homozygous for a null mutation of Meox2 have defects in limb muscle differentiation resulting in an overall reduction in muscle mass and absence of specific muscles (Mankoo et al., 1999). Meox1 mutant mice exhibit mild defects in sclerotome-derived vertebral and rib bones (Mankoo etal., unpublished). Compound mutant embryos (Meox ${ }^{-1-} ;$ Meox $2^{-1}$ ) displayed a dramatic phenotype associated with disrupted somite development; the axial skeleton failed to develop and most skeletal muscles were absent or reduced in size (Mankoo et al., 2003). These studies demonstrated that Meox 2 is required for limb muscle development and both Meox1and Meox2 have a critical concerted function during somite morphogenesis (Mankoo et al., 2003). To understand the function of these two transcription factors during chick embryogenesis requires a detailed knowledge of their expression at relevant stages of development.

In chick, Meox2 expression during development has been previously described (Rallis et al., 2001). Here, we describe for the first time in chick the distribution of Meox 1 and compare it to Meox2. Meox1 has both unique and overlapping expression domains with Meox2in chick and similar but not identical expression patterns to Meox 1 in mouse.
A chicken Meox1 cDNA clone, ChEST805f3, was obtained from the BBSRC Chicken EST Project (Hubbard et al., 2005). The nucleotide sequence homology of this clone showed $86 \%$ identity to human Meox 1 and $86 \%$ to murine Meox 1 .

Meox 1 expression first appears in the chick embryo at the time of formation of the headfold (stage 6, Hamburger and Hamilton, 1951 ) in the pre-somitic mesoderm (Fig. 1A). Expression in this domain continues through stage 7 (Fig. 1B) and at stage 8 is in the pre-somitic mesoderm and the first somites (Fig. 1C). A section through the embryo in Fig. 1B confirms that expression of Meox1 is in the pre-somitic mesoderm (psm, Fig. 1E, red arrows) and not in the ectoderm and endoderm. In the initial epithelial stage, the entire somite expresses Meox1. In mouse, like chick, Meox1 expression begins during the gastrulation stage (E7.0-7.5) in the posterior mesoderm (Candia et al., 1992). At stage 10, Meox1 expression is located in the developing somites and the most anterior pre-somitic mesoderm. There is strong expression in the posterior somites but the signal rapidly diminishes in the more rostral somites (Fig. 1D). By stage 14 chick Meox 1 expression is much stronger in the pre-somitic mesoderm and the most caudal somites suggesting a role for this gene in somite formation and differentiation (Fig. 1F, black arrow). The most anterior somites also show higher expression levels and correspond to cervical somites (Fig. 1F, CS, black band). The thoracic somites initially

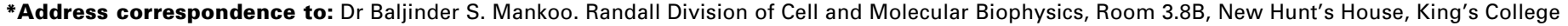
London, Guy's Campus, London, SE1 1UL, UK. e-mail: baljinder.mankoo@kcl.ac.uk
} 
have high Meox 1 expression, but as they mature this drops to a much lower level (Fig. 1F, TS, black band). Murine Meox1 expression at neurulation stages (E8.0-9.5) is described in intermediate and lateral plate mesoderm (Candia et al., 1992). In chick, in contrast, Meox 1 was not detected in intermediate and lateral plate mesoderm (Figs. $1 \mathrm{H}$ and 1I).

As previously described by Rallis and colleagues (Rallis et al., 2001), the onset of Meox2expression (Fig. 1J) is at stage 11 in all cervical somites, far later than that of Meox1. This is in contrast with murine Meox2 which is expressed from E8.0 onwards in all newly formed somites. At stage 16, unlike Meox1, Meox2expression is not detected in the pre-somitic mesoderm and is first seen in newly formed epithelial somites (compare Figs. 1G, red arrow with $1 \mathrm{~K}$, red arrow). Furthermore, Meox 2 expression is maintained at a high level in the somites unlike Meox 1 which de-
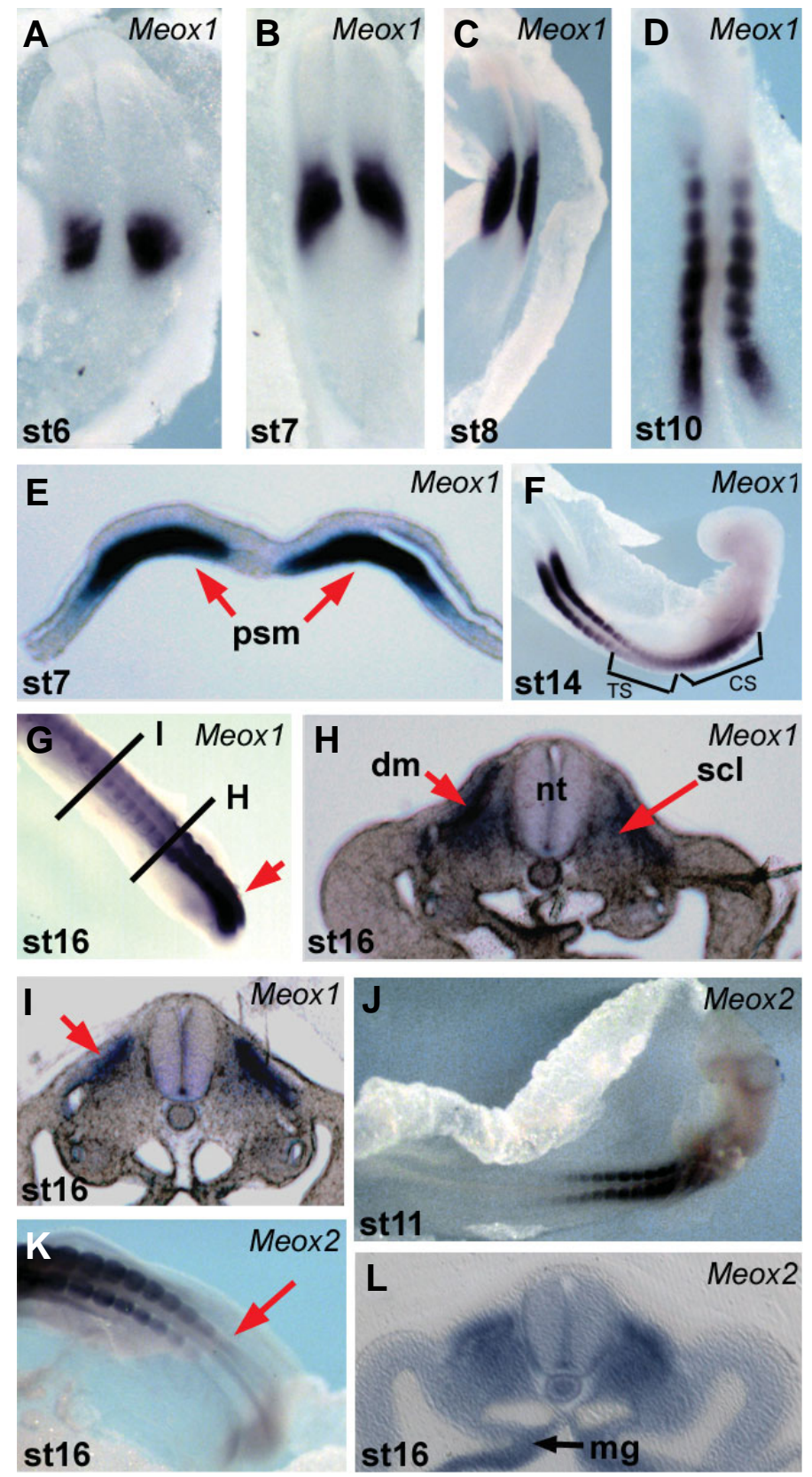

creases in mature somites. A transverse, vibratome section through the caudal somites of the stage 16 embryo in figure $1 \mathrm{G}$ (plane of section shown by black line, $\mathrm{H}$ ) shows that Meox1 expression is in both the dermomyotome and sclerotome ( $\mathrm{dm}$ and scl, red arrows, Fig. 1H). The dermomyotome gives rise to muscle and dermis and the sclerotome to cartilage and vertebrae. Figure 1 I shows a more rostral, transverse section through the embryo in figure $1 \mathrm{G}$ (plane of section shown by black line I) and reveals that Meox1expression is restricted to the dermomyotome (red arrow). At E9.5 the murine Meox 1 signal is detected in the dermomyotome and the sclerotome (Candia et al., 1992). Chick Meox2 is detected in the whole somite as shown by a transverse section through a stage 16 chick embryo (Fig. 1L). There is also expression in the developing mid-gut (Fig. 1L, mg, black arrow).

\section{Expression in stages 17-25 emphasises differences between Meox1 and Meox2}

In chick, there are very few changes in the expression of Meox1 from stage 16 to 20 . At stage 17 Meox 1 begins expression in the lateral rectus muscle of the eye and at stage 20, (Fig. 2A), the muscle precursors of the first pharyngeal arch. Its somitic expression is restricted to the posterior halves, strong expression continues in the tailbud and in the lateral rectus muscle, clearly visible in a region lateral to the eye. (Fig. 2A). A close-up of the head of the stage 20 embryo in Fig. 2A shows Meox 1 expression in the lateral rectus muscle (Fig. 2J, red arrow) and the first pharyngeal arch (Fig. 2J, black arrow). A close-up of the somitic domain confirms that Meox 1 expression is restricted to the posterior halves of the somites (Fig. 2L, red arrow). At stage 22, chick Meox1 expression is first detected in the fore limb buds (Fig. 2B, red arrow) and continues in the eye region (Fig. 2K) At stage 25, expression continues in the eye domain, somites, tail bud and the limb buds signal is stronger (Fig. 2C, red arrows). Extended

Fig. 1. Expression patterns of Meox1 (A-I) and Meox2 (J-L) in stage 6-16 chick embryos. (A) Expression of Meox 1 begins at stage 6 in the pre-somitic mesoderm. Expression continues in this region through stages 7 and 8 (B-C) until stage 10 when it becomes localised in the developing somites (D). (E) A transverse vibratome section through a stage 7 embryo confirms that Meox1 expression is in the pre-somitic mesoderm (psm, red arrows). (F) At stage 14, Meox1 expression continues in the somites with strong expression in the most caudal somites and the as yet undifferentiated pre-somitic mesoderm (black arrowhead). The cervical somites exhibit strong Meox 1 expression, (CS) and the thoracic somites (TS) initially have strong expression, decreasing as the somites mature. (G) At stage 16, Meox1 is still expressed in the somites and strong expression continues in the tail bud (red arrow). (H) Sections through the caudal somites of the embryo in (G) (marked by black line - H), show Meox1 expression throughout the somite in the dermomyotome (dm, red arrow) and the sclerotome (scl, red arrow). (I) Rostral transverse sections through the stage 16 embryo in $G$ (black line $-1)$, reveal that Meox1 expression in the rostral somites is restricted to the dermomyotome (red arrow). (J) Meox2 expression begins at stage 11 in the developing somites. (K) At stage 16, Meox2 expression continues in the somites but not in the pre-somitic mesoderm [compare $(G)$ and $(K)$ red arrows]. (L) A transverse section through the somites of the embryo in (K) shows Meox2 expression in the dermomyotome and the sclerotome and the developing mid-gut (mg, black arrow). Abbreviations: cs, cervical somites; dm, dermomyotome; mg, mid-gut; $n t$, neural tube; psm, pre-somitic mesoderm; scl, sclerotome; st, stage; ts, thoracic somites. 
staining revealed additional sites of expression (Fig. 2D) namely the oesophagus (o), truncus arteriosus of the heart (ta) and the dorsal somites (black arrow). As in chick, the mouse Meox 1 signal at E11.5 is also detected lateral to the eye (Fig. 2G, upper red arrow). At E11.5 murine Meox1expression is similar to chick expression in the somites with stronger expression in the caudal somites and expression begins in the limb bud (Fig. 2G) and the pharyngeal arches (Fig. 2G, lower red arrow). At later stages, murine Meox 1 expression has also been reported to be localised to regions of the developing heart (truncus arteriosus) (Candia et al., 1992).

From stages 16 to 20 , the chick Meox2 signal, like Meox1, does not dramatically change. At stage 20 Meox 2 expression is found in the posterior halves of the somites, similar to Meox1 (Fig. 2E). In limb buds, Meox2 expression is first observed in stage 21 chick embryos (this study and Rallis et al., 2001). A lateral view of a stage 25 chick embryo shows strong Meox2 expression in the developing limb buds(Fig. 2F, red arrows) and expression continues in the somites (Fig. 2F). A new domain of expression begins at this stage, the $2^{\text {nd }}$ pharyngeal arch (Fig. 2F, white arrow). In chick, unlike Meox 1, there is no Meox 2 expression detected in the heart. Stage 25 chick embryos were hybridised with Pax3 for comparison with Meox 1 and Meox 2 expression in the somites. Figure $2 \mathrm{H}$ shows Pax3expression in the limbs at stage 25 and is expressed in the epithelial dermomyotome with strong expression in the ventral domain of the somites. Scleraxis expression at stage 25 in the chick is in the limb buds and the intersomitic mesenchyme (Fig. 2I).

\section{Expression in stage 22 and 25 hind limb buds}

Avian Pax3 (Goulding et al., 1994); Scleraxis(Schweitzer etal., 2001); MyoD and Myf5(Pownall and Emerson, 1992) expression patterns have been previously described. Here they are used for comparison of Meox1 and Meox2 expression in hind limbs of stage 22 and stage 25 chick embryos. Figures $3 \mathrm{~A}-\mathrm{F}$ upper panel, shows the hind limbs of stage 22 embryos where the myogenic pathway has been activated and prolif-
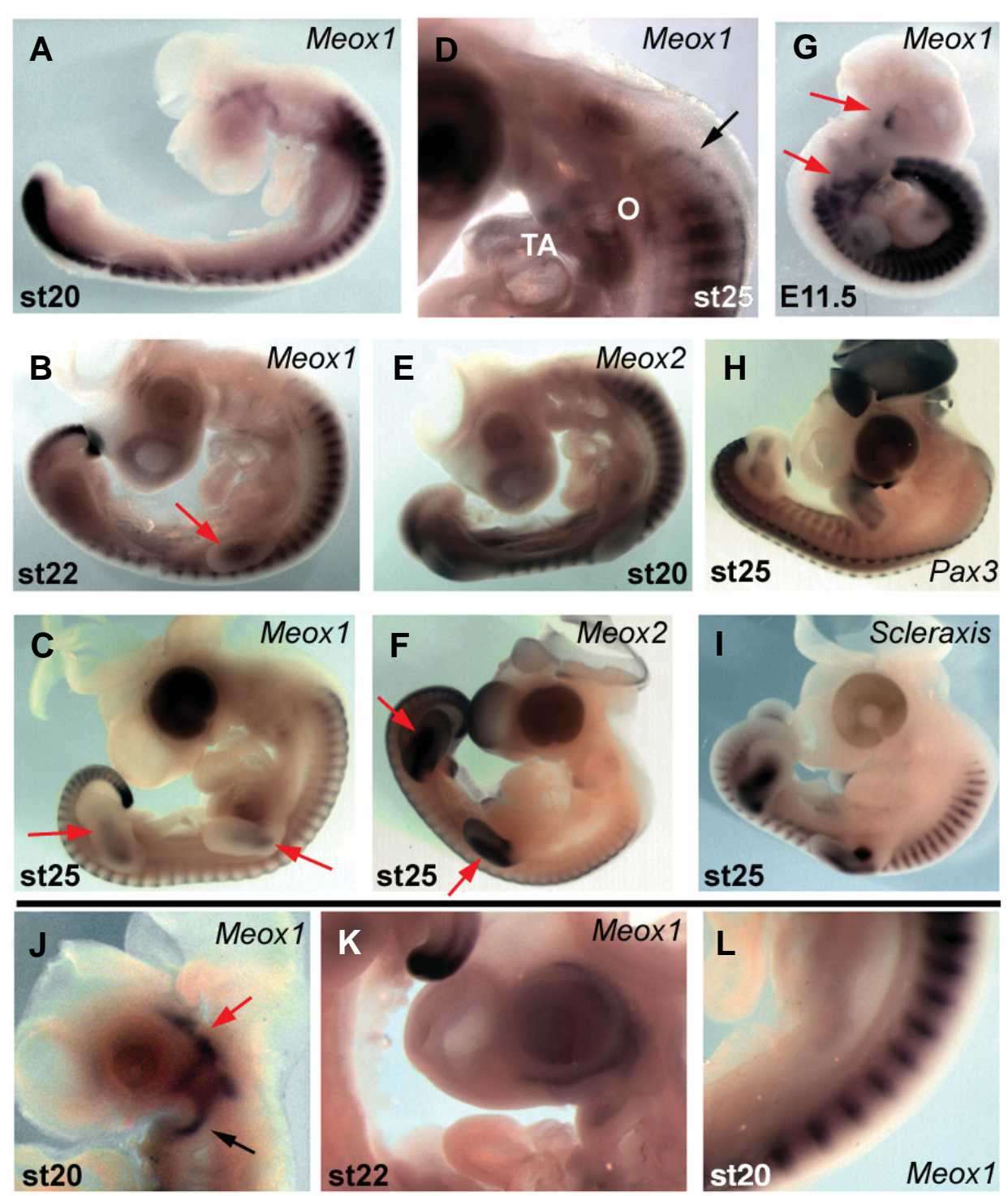

Fig. 2. Expression patterns of Meox1 (A-D, J-L), Meox2 (E-F), Pax3 (H) and Scleraxis (I) in stage 20-25 chick embryos and Meox 1 in an E11.5 mouse embryo (G). (A) A lateral view of Meox 1 in a stage 20 embryo showing expression in the tail bud, posterior halves of somites, the lateral rectus muscle and the muscle of the first pharyngeal arch. (B) At stage 22 the same expression domains are present as in (A) and expression now begins in the limb buds, red arrow. (C) At stage 25, expression in the wing and leg buds is more pronounced, red arrows. (D) A close-up of a stage 25 embryo reveals Meox1 expression in the dorsal region of the most anterior somites (black arrow), the $4^{\text {th }}$ and $5^{\text {th }}$ pharyngeal arches, the truncus arteriosus of the heart (ta) and oesophagus (o). [N.B. the staining around the otic vesicle in (D) is non-specific]. (E) At stage 20, Meox2 expression is in the posterior halves of the somites. (F) Meox2 is strongly expressed in the limb buds by stage 25 (red arrows) and the $2^{\text {nd }}$ pharyngeal arch (white arrow). (G) Meox1 expression in an E11.5 mouse embryo shows expression in the somites, the pharyngeal arches (lower red arrow) and a region lateral to the eye (upper red arrow). (H) Pax3 expression is detected in the limbs at stage 25 and in the epithelial dermomyotome of the somites, with stronger expression in the ventral domain. (I) Scleraxis expression at stage 25 is in the intersomitic mesenchyme and limb buds. (J) A close-up of the embryo in (A), showing Meox 1 expression in the lateral rectus muscle of the eye, red arrow and the first pharyngeal arch (black arrow). (K) A close-up of a stage 22 embryo where the eye domain expression continues. (L) A stage 20 embryo showing Meox1 expression in the posterior halves of the somites. Abbreviations: o, oesophagus; ta, truncus arteriosus. 

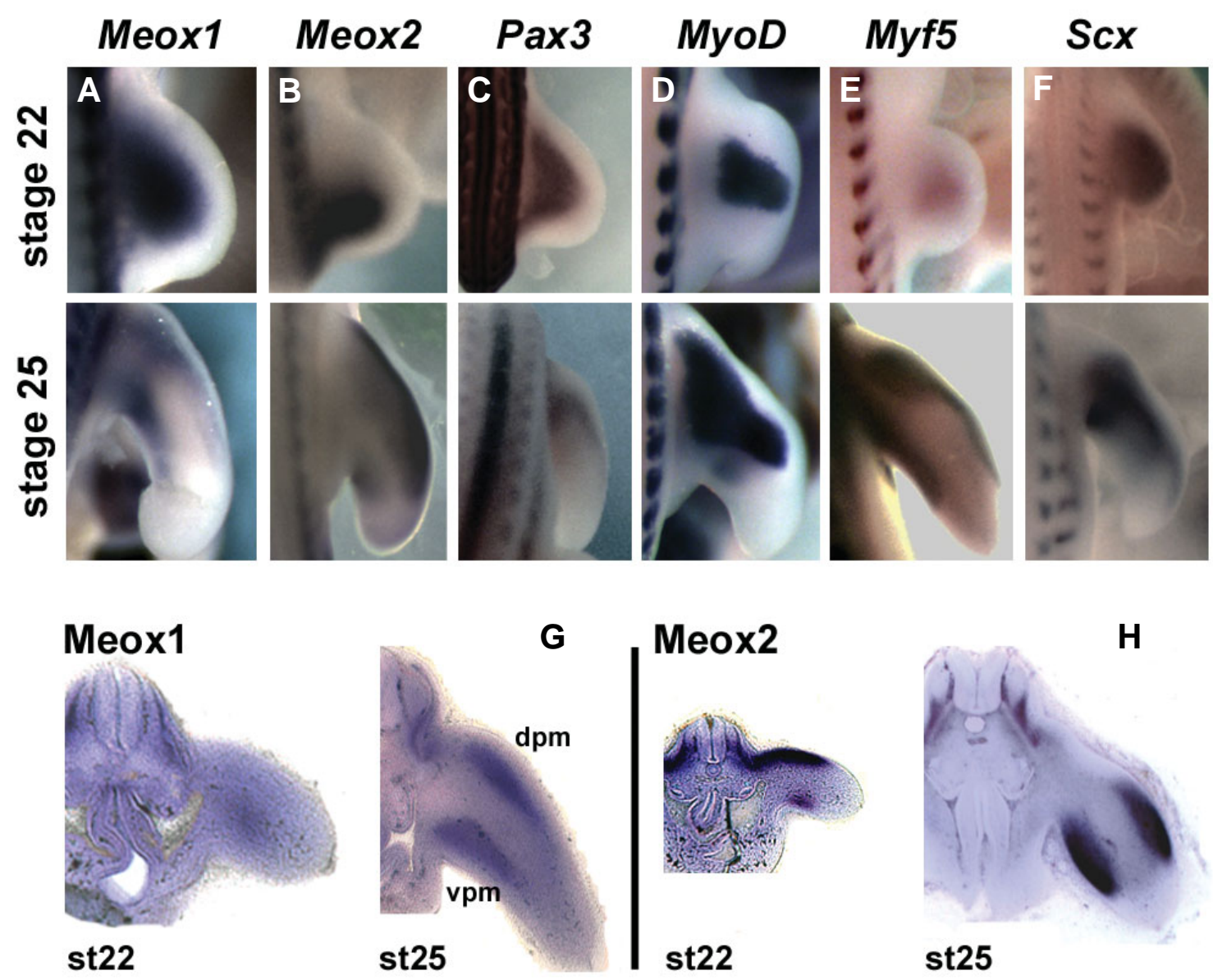

Meox2
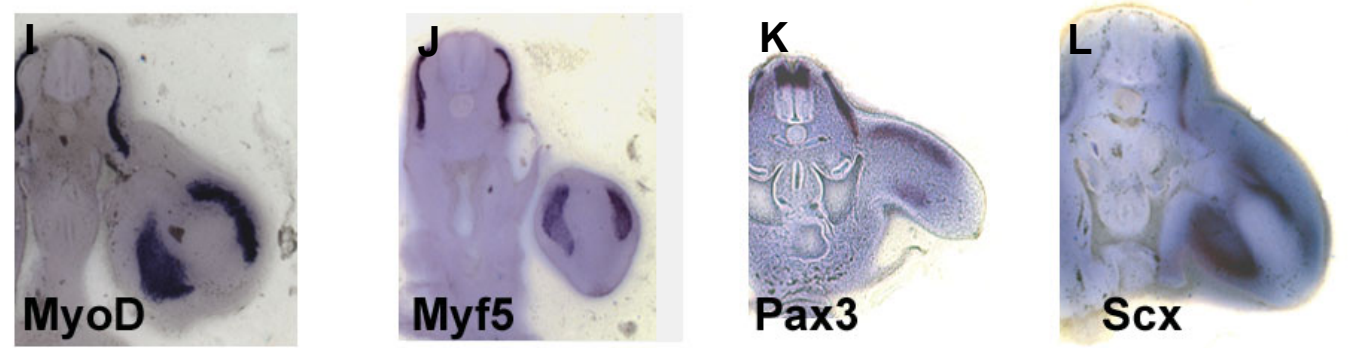

Fig. 3. Meox 1 and Meox 2 expression in stage 22 and 25 chick hind limb buds compared with Pax3, MyoD, Myf5 and Scleraxis at equivalent stages. (A-F) Dorsal views of hind limb buds of stage 22 (upper panel) and stage 25 (lower panel) chick embryos stained for expression of Meox1 (A), Meox2 (B), Pax3 (C), MyoD (D), Myf5 (E) and Scleraxis (Scx), (F). (G) Transverse sections through the stage 22 hind limb in (A) (upper panel) shows Meox1 expression in the dermomyotome and ventral to the central core of the limb and at stage 25 embryo Meox 1 expression continues in the dermomyotome and in the same region as the dorsal pre-muscle mass (dpm) and the ventral pre-muscle mass (vpm). (H) Transverse section of a stage 22 chick embryo stained for the expression of Meox2. Note the Meox2-positive muscle precursor cells migrating from the dermomyotome into the limb bud. At stage $25 \mathrm{Meox} 2$ expression is located in a region of the limb corresponding to the dorsal and ventral pre-muscle masses. The expression of the Meox1 (G) and Meox2 (H) genes at stage 25 is similar to other myogenic markers at this stage such as MyoD (I), Myf5 (J) and Pax3 (K). (L) This is in contrast to the expression of Scleraxis at stage 25 in the somites-Scleraxis is expressed in the syndetome-and the limb buds. Abbreviations: dpm, dorsal pre-muscle mass; vpm, ventral pre-muscle mass.

erating cells expressing myogenic markers Pax3(Fig. 3C) MyoD (Fig. 3D), Myf5(Fig. 3E) and the tendon marker, Scleraxis (Scx, fig. 3F) can be seen. Meox 1 and Meox2 positive cells are also detected in stage 22 limb buds (Figs $3 A$ and $3 B$ respectively).

In figures $3 \mathrm{~A}-\mathrm{B}$, lower panel, Meox 1 and Meox2 transcripts are detected in stage 25 chick hind limbs and at this stage Pax3,
MyoD, Myf5 and Scleraxis are also detected in hind limbs (Figs. C-F, lower panel).

Transverse sections were cut from stage 22 and stage 25 hind limbs to determine where Meox 1 and Meox 2 are expressed. Meox 1 is expressed in the dermomyotome at stage 22 and transcripts can be detected in the proximal domain, ventral to the 
central core of the hind limb but sectioning at the limb level did not show evidence of staining in limb muscle progenitors migrating from the dermomyotome (Fig. 3G, left side). At stage 25, expression is still detected in the dermomyotome and there is now strong expression in the dorsal and ventral limb mesoderm, apparently overlapping with the dorsal and ventral premuscle masses (dpm, vpm, Fig. 3G, right side). At stage 22, Meox2 positive myoblasts are migrating from the dermomyotome into the dorsal and ventral hind limb (Fig. 3H, left side). At stage 25, Meox2 transcripts are observed in the dermomyotome and in the same region as the dorsal and ventral pre-muscle masses (Fig. 3H, right side). Transverse sections of stage 25 hind limbs were in situhybridised with myogenic markers MyoD (Fig. 3I), Myf5 (Fig. 3J) and Pax3 (Fig. 3K). These show that Meox1 and Meox2 transcripts appear to localise to the same domains as these myogenic marker genes, namely the dermomyotome and the dorsal and ventral pre-muscle masses. The domains of Scleraxis expression are slightly different at stage 25 (Fig. 3L). In the somite it is located to the syndetome and the limb, in cells beginning to coalesce into tendon precursors.

In the developing mouse embryo limb buds at E9.75 and E10.75, Meox2 is expressed in the somite derived myoblasts that coalesce to form the dorsal and ventral pre-muscle masses; Meox1 mRNA was not detected in the limb bud at these stages (Mankoo et al., 1999). We detected low levels of the Meox1 signal at E11.5 in the limb buds in the dorsal and ventral mesenchyme (data not shown).

To determine the identity of the cells in the dorsal and ventral pre-muscle mass regions that express Meox1 and Meox2, two-colour fluorescence labelled in situ hybridisation was performed on transverse cryosections of stage 25 chick limbs. Figure $4 \mathrm{~A}-\mathrm{O}$ shows confocal images at high magnification (20X) in the same region as the dorsal pre-muscle mass (see Fig. 3G, $\mathrm{dpm}$ ). The domain of Meox1 (green) expressing cells slightly overlaps with but shows no co-expression with the Pax3 (red) positive myogenic precursor cells (Figs. 4A-C). Double labelling for Meox1 (green) and the committed myogenic precursor marker gene $M y o D$ (red) show expression in the same domain but not in the same cells (Figs. 4D-F). Meox2 (green) and Pax3 (red) expression overlap with a proportion of cells co-expressing both genes (Figs. 4G-I). Meox2 (green) and $M y o D$ (red) have adjacent, non-overlapping expression domains in the distal limb with Meox2 in the peripheral limb mesoderm (Figs. 4J-L) whereas in the
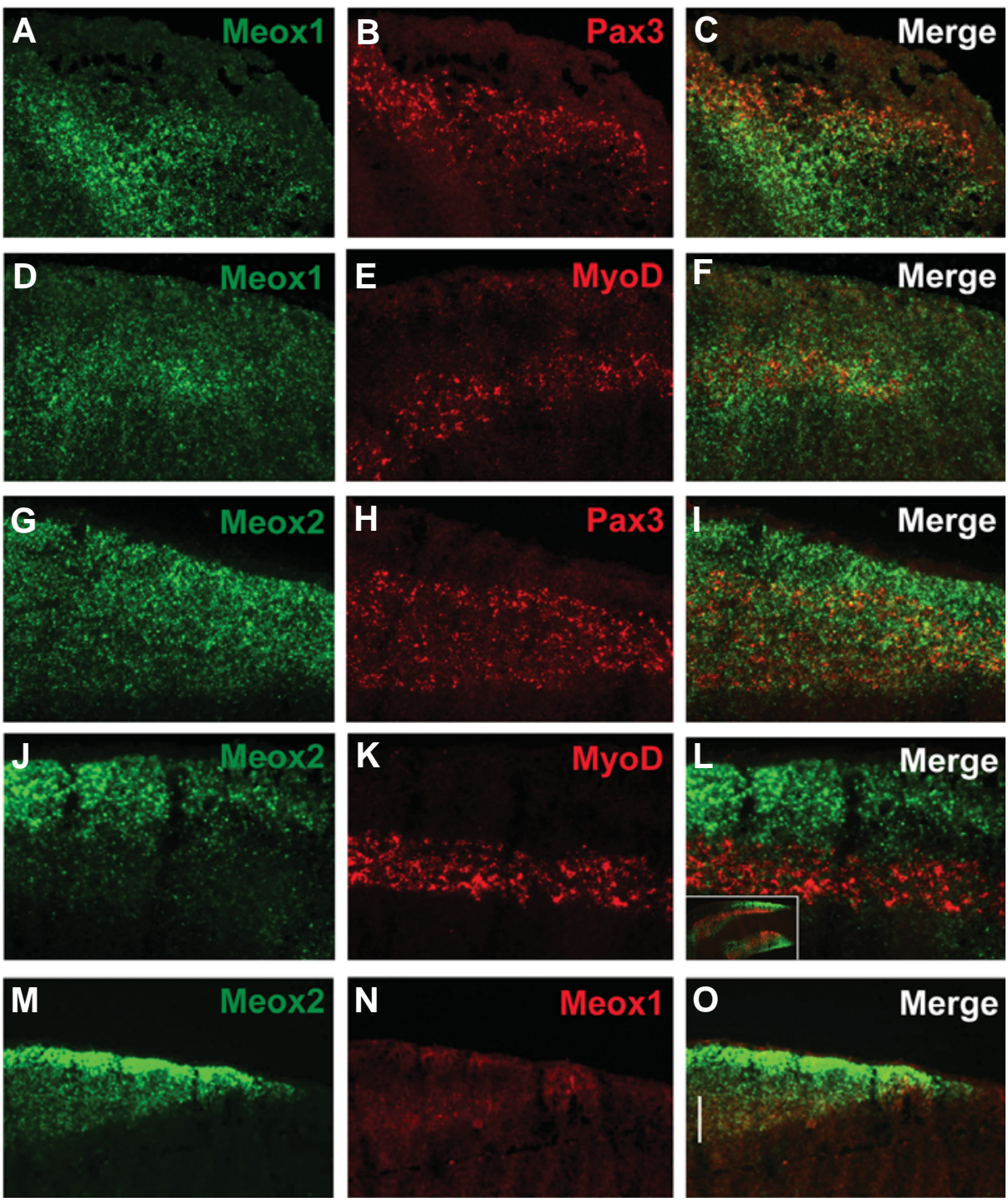

Fig. 4. Two-colour fluorescent in situ hybridisations with Meox 1 and $P a x 3$ (A-C), Meox 1 and MyoD (D-F), Meox2 and Pax3 (G-I), Meox2 and $M y o D(J-L)$ and Meox2 and Meox1 (M-O) on transverse sections of stage 25 chick hind limbs. Expression domains of Meox1 (green) (A) and Pax3 (red) (B) slightly overlap but are not co-expressed (C). Meox1 (green) (D) and MyoD ( red) overlap, a few cells show co-expression (I). Meox2 (green) (J) and MyoD (red) (K) are not expressed in the same cells (L). Meox2 (green) (M) and Meox1 (red) (N) exhibit a narrow band of co-expression (depicted by a white line in $(\mathbf{0})$ ), suggesting separate roles for these two genes during chick limb development.

proximal limb domain, the two expression domains overlap but there is no co-expression (see Fig. 4L, inset). Meox2 (Fig. 4M, green) and Meox1 (Fig. 4N, red) have abutting domains of expression with regions of overlap but Meox 2 is expressed in a more peripheral, broader domain in the dorsal and ventral limb mesenchyme than Meox 1 and there is a narrow region of overlap where both genes are co-expressed (Fig. 4O, white line).

Table 1 compares the similarities and differences between the expression domains of Meox 1 and Meox 2 in chick and mouse at equivalent developmental stages.

Summarising, chick Meox1 and Meox2 have similar but distinct spatial-temporal expression patterns during early devel- 
TABLE 1

\section{COMPARISON OF MEOX1 AND MEOX2 EXPRESSION PATTERNS IN CHICK AND MOUSE DURING EARLY EMBRYOGENESIS}

\begin{tabular}{|c|c|c|}
\hline & CHICK & MOUSE \\
\hline & HH st. 6 (Headfold - pre-somitic) & E7-7.25 (Headfold - pre-somitic) \\
\hline Meox1 & Pre-somitic mesoderm & Pre-somitic mesoderm \\
\hline \multirow[t]{2}{*}{ Meox2 } & No expression detected at this stage & No expression detected at this stage \\
\hline & HH st. $7-10$ ( $1-10$ somites $)$ & E7.5-8.5 (5-13 somites) \\
\hline Meox1 & Developing somites, anterior pre-somitic mesoderm & $\begin{array}{l}\text { Somitic, intermediate and lateral plate mesoderm, developing somites, anterior } \\
\text { pre-somitic mesoderm }\end{array}$ \\
\hline \multirow[t]{2}{*}{ Meox2 } & No expression detected at this stage & Expression begins at E8.0 in the entire epithelial somite \\
\hline & HH st. 11-16 (13-28 somites) & E9-10.25 (14-30 somites) \\
\hline Meox1 & $\begin{array}{l}\text { Anterior pre-somitic mesoderm, dermomyotome in rostral somites, } \\
\text { dermomyotome and sclerotome in caudal somites }\end{array}$ & $\begin{array}{l}\text { Somitic, intermediate and lateral plate mesoderm, dermomyotome and } \\
\text { sclerotome of somites }\end{array}$ \\
\hline \multirow[t]{2}{*}{ Meox2 } & $\begin{array}{l}\text { Expression begins at stage } 11 \text { in all cervical somites, at } \\
\text { stage } 16 \text { in dermomyotome and sclerotome, developing mid-gut }\end{array}$ & Expression is restricted to sclerotome of somites \\
\hline & HH st. $17-22(29-43$ somites $)$ & E10.5-11.5 (35-45 somites) \\
\hline \multirow{3}{*}{$\begin{array}{l}\text { Meox1 } \\
\text { Meox2 }\end{array}$} & Lateral rectus muscle, posterior halves of somites, limb buds, $1^{\text {st }}$ pharyngeal arch & Eye muscle, limb buds, somites, pharyngeal arches, developing kidneys \\
\hline & Posterior halves of somites, limb buds & Limb buds, somites, pharyngeal arches and derivatives \\
\hline & HH st. $22-25$ & E12.5 \\
\hline Meox1 & $\begin{array}{l}\text { Eye domain, somites and dorsal somites, tail bud, limb buds, oesophagus, } \\
\text { truncus arteriosus of heart }\end{array}$ & $\begin{array}{l}\text { Eye domain, truncus arteriosus of heart, developing kidneys, pharyngeal arches } \\
\text { and derivatives }\end{array}$ \\
\hline Meox2 & Limb buds, somites, $2^{\text {nd }}$ pharyngeal arch & Limb buds, somites, pharyngeal arches and derivatives \\
\hline
\end{tabular}

opment and somitic differentiation. Meox 1 is expressed earlier and initially both are expressed over the whole epithelial somite. Meox 1 has strong expression in the pre-somitic mesoderm whereas Meox2transcripts are absent in this domain. In the newly formed somites, Meox 1 transcripts are detected throughout the somite in the sclerotome and dermomyotome. When the somites differentiate, Meox 1 expression is restricted to the dermomyotome. Meox2 is expressed throughout the whole somite and its expression is maintained along the axis whereas Meox 1 expression is strongest in most caudal somites and is much reduced more anteriorly. Both genes appear conserved between chick and mouse. In the chick limb, two-colour fluorescent in situhybridisation revealed that neither Meox1 nor Meox2 transcripts had overlap with $M y O D$ expressing cells. This technique also revealed that chick Meox 1 and Meox2, although both being expressed in the same regions as the dorsal and ventral pre-muscle masses, show only a small domain of co-expression.

Meox 1 and Meox 2 have overlapping domains of expression which suggest overlapping functions. However, within developing somites and the limb bud the non-overlap of expression indicates these genes have distinct and unique functions.

\section{Experimental Procedures}

Fertilized chicken eggs were staged according to Hamburger and Hamilton (Hamburger and Hamilton, 1951).

Full-length chick Meox2 cDNA was cloned in pBluescript $\mathrm{KS}(+/-)$ (Stragene) and to generate digoxigenin (DIG) labelled (Roche) antisense probe, cut with Sacl and transcribed with T3 RNA polymerase (Roche). Scleraxis anti-sense probe was generated from ChEST973H2 cDNA from the BBSRC Chicken EST Project, cloned into pBluescript KS II, cut with Not1 and transcribed with T3. Meox1 antisense-probe was generated from ChEST805F3, cloned into pBluescript KS II, cut with Notl and transcribed with T3. MyoD, Pax3 and Myf5 anti-sense probes were a kind gift of Philippa Francis-West. Full-length mouse Meox1cDNA was cloned into pBluescript KS II, cut with Pstl and transcribed with T3. Wholemount in situ hybridisation was carried out using standard procedures.

Two-colour fluorescence in situhybridisation was performed on fresh frozen sections as described by Tylzanowski et al. (2003). FITC-labelled probes were used instead of biotin-labelled probes and detected by antiFITC-POD (Roche 1426346). Proteinase K digestion at $1 \mu \mathrm{g} / \mathrm{ml}$ for 5-7 mins was used for tissue permeabilisation.

\section{Acknowledgements}

We thank Professor Malcolm Maden for critical reading of the manuscript and Professor Stefan Mundlos for the generous use of reagents and equipment. S.R. is funded by the BBSRC.

\section{References}

CANDIA A.F., HU J., CROSBY J., LALLEY P.A., NODEN D., NADEAU J.H. and WRIGHT C.V. (1992). Mox-1 and Mox-2 define a novel homeobox gene subfamily and are differentially expressed during early mesodermal patterning in mouse embryos. Development 116: 1123-1136.

GOULDING M., LUMSDEN A. and PAQUETTE A.J. (1994). Regulation of Pax-3 expression in the dermomyotome and its role in muscle development. Development 120, 957-971.

HAMBURGER V. and HAMILTON H.L. (1951). A series of normal stages in the development of chick embryo. J. Morphol. 88, 49-92.

HUBBARD S.J., GRAFHAM D.V., BEATTIE K.J., OVERTON I.M., MCLAREN S.R., CRONING M.D., BOARDMAN P.E, BONFIELD J.K, BURNSIDE J., DAVIES R.M., FARRELL E.R., FRANCIS M.D., GRIFFITHS-JONES S., HUMPHRAY S.J., HYLAND C., SCOTT C.E., TANG H., TAYLOR R.G., TICKLE C.,'BROWN W.R., BIRNEY E., ROGERS J. and WILSON S.A. (2005) Transcriptome analysis for the chicken based on 19,626 finished cDNA sequences and 485,337 expressed sequence tags. Genome Res. 15:174-83

MANKOO B.S., COLLINS N.S., ASHBY P., GRIGORIEVA E., PEVNYL.H., CANDIA A., WRIGHT C.V., RIGBY P.W. and PACHNIS V. (1999). Mox2is a component of the genetic hierarchy controlling limb muscle development. Nature 400:4973.

MANKOO B.S., SKUNTZS., HARRIGAN I., GRIGOREVA E., CANDIA A., WRIGHT C.V., ARNHEITER H. and PACHNIS V. (2003). The concerted action of Meox homeobox genes is required upstream of genetic pathways essential for the formation, patterning and differentiation of somites. Development 130. 46554664.

POWNALL M.E. and EMERSON C.P. (1992). Sequential activation of three myogenic regulatory genes during somite morphogenesis in quail embryos. Dev. Bio. 151, 67-79.

RALLIS R., STAMATAKI D., PONTIKAKIS S., MANKOO S. and KARAGOGEOS D. (2001). Isolation of the avian homologue of the homeobox gene Mox2 and analysis of its expression pattern in the developing somites and limbs. Mech. 
Dev. 104, 121-124.

SCHWEITZER R., CHYUNG J., MURTAUGH L.C., BRENT A.E., ROSEN V., OLSON E., LASSAR A. and TABIN CJ. (2001). Analysis of the tendon cell fate using Scleraxis, a specific marker for tendons and ligaments. Development 128 3855-3866.
TYLZANOWSKI P., DE VALCK D., MAES V., PEETERS J. and LUYTEN F.P. (2003). Zfhxla and Zfhz1b mRNAs have non-overlapping expression domains during chick and mouse midgestation limb development. Gene Expr. Patt. 3, 3942.

Published Online: 17 th July 2007

\section{Related, previously published Int. J. Dev. Biol. articles}

See our Special Issue on Limb Development edited by Juan Hurlé and Juan Carlos Izpisua Belmonte at: http://www.ijdb.ehu.es/web/contents.php?vol=4\&6issue $=7$

See our recent Special Issue on Ear Development edited by Fernando Giraldez and Bernd Fritzsch at: http://www.ijdb.ehu.es/web/contents.php?vol=51\&issue=6-7

Gene expression analysis reveals that formation of the mouse anterior secondary palate involves recruitment of cells from the posterior side

Qun Li and Jixiang Ding

Int. J. Dev. Biol. (2007) 51: 167-172

Sclerotome development and morphogenesis: when experimental embryology meets genetics Anne-Hélène Monsoro-Burq

Int. J. Dev. Biol. (2005) 49: 301-308

Common mechanisms for boundary formation in somitogenesis and brain development: shaping the 'chic' chick

Yoshiko Takahashi

Int. J. Dev. Biol. (2005) 49: 221-230

Expression of csal1 in pre limb-bud chick embryos

Dylan Sweetman, Terence G. Smith, Elizabeth R. Farrell and Andrea Münsterberg

Int. J. Dev. Biol. (2005) 49: 427-430

Molecular mechanisms controlling dorsal dermis generation from the somitic dermomyotome. Isabel Olivera-Martinez, Jacques Thélu and Danielle Dhouailly

Int. J. Dev. Biol. (2004) 48: 93-101

Vertebrate somitogenesis: a novel paradigm for animal segmentation?

Olivier Pourquié

Int. J. Dev. Biol. (2003) 47: 597-603

Type I cadherins are required for differentiation and coordinated rotation in Xenopus laevis somitogenesis.

Emiliana Giacomello, Jerome Vallin, Olivier Morali, Ivan $S$ Coulter, Habib Boulekbache, Jean P Thiery and Florence Broders

Int. J. Dev. Biol. (2002) 46: 785-792

Differential localization of Mox-1 and Mox-2 proteins indicates distinct roles during development.

A F Candia and C V Wright

Int. J. Dev. Biol. (1996) 40: 1179-1184

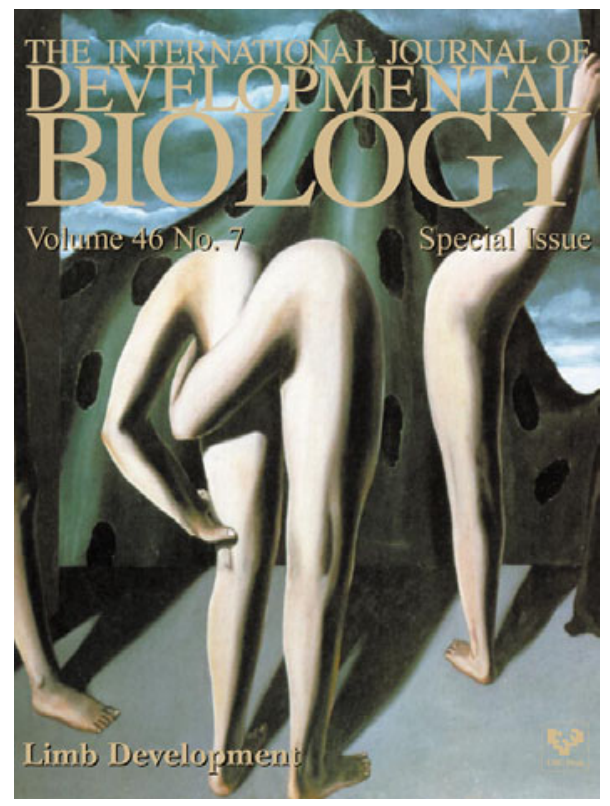

